\title{
Impact of Intervention on Psychological Wellbeing of Adolescent Girls from Agrarian Families
}

\author{
Nasreen Banu* and K. Yashoda
}

AICRP- H.Sc (All India Coordinated Research Project - Home Science), Human Development Component, PGRC, PJTSAU (Professor Jayashankar Telangana State Agricultural

University), Rajendranagar, Hyderabad - 30, Telangana State, India

*Corresponding author

A B S T R A C T

\section{Keywords}

Psychological wellbeing,

Intervention programme,

Counseling sessions,

Rural adolescent girls

Article Info

Accepted:

18 October 2018

Available Online:

10 November 2018
Present study was taken up to find out the impact of Intervention on the psychological wellbeing of rural adolescent girls (50) from the adopted villages (3) of Maheshwarammandal, RR district, Hyderabad. Impact assessment showed significant improvement in the Psychological wellbeing of the sample, reflecting the effectiveness of the Intervention programme (Counseling sessions).

\section{Introduction}

Adolescence is usually associated with the teenage years but its physical, psychological or cultural expressions may begin earlier and end later. For example, puberty now typically begins during preadolescence, particularly in females. Physical growth (particularly in males), and cognitive development can extend into the early twenties. Thus age provides only a rough marker of adolescence, and scholars have found it difficult to agree upon a precise definition of adolescence. According to psychological well-being theory, individual's psychological health depends on his positive functioning in certain aspects of his life. Individual should have in positive relationship with others; should be dominant over the environment; should accept himself and his past; should has a goal and meaning in his life; should have personal development and the ability to make his own decisions (Özen, 2005). For this reason, there is a potential tension between psychological well-being, happiness, and development (Ryff and Singer, 1998). Psychological well-being takes an important part in personality and development theories both theoretically and practically. 
Psychological well-being, which guides clinical studies that will help advisors to make their advisees reach their goals, informs about the goals and purposes regarding psychology consulting (Christopher, 1999).

Adolescents' psychological well-being and perceived parental involvement: implications or parental involvement in middle schools was studied by Kayla Cripp and Brett Zyomski (2009).

And the findings were; perceived parental involvement positively or negatively affects adolescents' sense of psychological wellbeing, notably in regard to self-esteem and self- evaluation, peer relationships, and frequency of negative familial life evens.

Adolescents determine personal self-worth, self-efficacy, and self-esteem based on perceptions gained from parental involvement as a result perceived parental involvement essential to an adolescent's psychological well-being.

Psychological wellbeing of adolescents means being content with life and understanding an abundance of positive emotions, when joined with the absence of psychopathology, is linked with greatest academic function, social skills and support and physical health, being a stage that lays strong foundation for future personality, and a critical period during human development in which life goals, values, direction and purpose in life are created (Jessica A; Berman S.L et al.,), guaranteeing psychological wellbeing of adolescents is a socio psychological necessity.

\section{Operational definition}

\section{Agrarian families}

Families involved in Agriculture for their livelihood

\section{Intervention}

An intervention is a combination of programme elements or strategies designed to produce behavior changes or improve health status among individuals or an entire population.

Counselling is face-to-face communication through a dynamic process of interaction between two or more people during which the counsellor helps the client to take decisions. It involves active listening to people talking about their problems; giving them comfort in an atmosphere of empathy and helping them to work out what to do about their problems, working at the empowerment of the client.

Counselling is a helping relationship aimed at enabling a client to explore a personal problem, giving the client increased awareness of choices than what they already have in dealing with the problem, and assisting her/him to make an informed decision what to do about the problem.

\section{Wellbeing}

Wellbeing, put simply, is about 'how we are doing' as individuals, communities and as a nation and how sustainable this is for the future. Personal wellbeing is a particularly important dimension which we define as how satisfied we are with our lives, our sense that what we do in life is worthwhile, our day to day emotional experiences (happiness and anxiety) and our wider mental wellbeing.

\section{Materials and Methods}

Sample was identified from the adopted village of Maheshwarammandal, RR District, Hyderabad, through field survey and focused group interviews with the help of the AWWs, ANMs, and Women Self-help Group leaders in the village. 
It's a quasi-experiment study. It is an empirical interventional study used to estimate the causal impact of an intervention on its target population without random assignment.

There were 110 adolescent girls in the age group of 16-19 years in the selected clusters of 4 villages namely Dubbacharla, Kollapadkal, Subhanpur \& Pendyala, of Maheshwarammandal and 50 formed the sample for the present study. The following criterion was used to select the sample. Purposive sampling procedure was used.

\section{Criteria for sample selection}

Rural girls who were involved in Agriculture

Rural girls who were willing to participate in the project

\section{General objective}

Promoting Psychological wellbeing among Ruraladolescent girls from Agrarian families

\section{Specific objectives}

To find out the demographic profiles of the Selected sample

To find out the Psychological wellbeing of the Selected sample

To conduct Intervention programme (Counselling sessions) to the selected sample

To assess the impact of the Intervention programme on the Psychological wellbeing of the selected sample

\section{Research strategy adopted}

In order to achieve the above objectives, Counselling sessions (10) were organized for the Rural adolescent girls.

\section{Research tools details}

SES scale developed by Aggrawal et al., (2005) was used to find out the SES of the Rural families. Scoring was given as per the norms provided in the manual. It is a standardized scale, used to assess the family background information of the individuals, which includes parameters like educational and occupational status of parents, number of siblings, material possession, kind of locality, presence of farm animals, land holdings, number of earning members in the family etc. The scale categorizes the sample on: Upper High; High; Upper middle; Lower middle; Poor and Very poor Socio Economic Status.

Psychological wellbeing scale, developed by Chassney (2014): It comprises of 5 dimensions: Physical, Social, Emotional, Spiritual and Intellectual. Each dimension has 10 statements and the statements are scored on a 4 point scale: Rarely is given a score of one, Sometimes is given a score of 2, Most of the time is given a score of 3 and Always is given a score of 4. Minimum score is 10 and 40 is the maximum score. Based on the scores, it categorized as Very good; Good; Average and Poor. The Reliability Value of the scale is: 0.74

\section{Results and Discussion}

\section{Demographic data on Adolescent girls from farming familes}

There were 110 adolescent girls in the age group of 16-19 years in the selected clusters of 4 villages namely Dubbacharla, Kollapadkal, Subhanpur and Pendyala, of Maheshwarammandal and 50 formed the sample for the present study.

The following criterion was used to select the sample. Purposive sampling procedure was used. 
The table 1 depicts the Education wise distribution of Rural adolescent girls (Table $1)$.

Out of the total sample 50, forty four percent of the sample completed Secondary school; $32 \%$ completed Inter; 14\% completed Primary school and $10 \%$ were illiterates.

The table 2 depicts the Occupation wise distribution of Rural adolescent girls.

Out of the total sample 50, fifty percent of the sample were fully involved in agriculture; $40 \%$ were partially involved in agriculture; and $10 \% \%$ were attending to household work.

The table 3 depicts the Socio Economic Status of Rural adolescent girls. Out of the total sample 50, more than half of (72\%) the sample were in lower middle income level; $18 \%$ were in upper middle income level and $10 \%$ were in poor economic status.

The table $4 \mathrm{a}$ traces the pretest scores of Adolescent girls with regard to Psychological Wellbeing. The scale covers 5 dimensions.

With regard to Physical Health dimension, 28 (56\%) obtained Good scores; 12 (24\%) obtained Average scores; and 10 (20\%) obtained very good scores.

With regard to Social Health dimension, 28 (56\%) obtained Good scores; 13 (26\%) obtained Very Good scores and 9 (18\%) obtained Average scores.

With regard to Emotional Health dimension, 31 (62\%) obtained Good scores; 11 (22\%) obtained very good scores and 8 (16\%) obtained Average scores.

With regard to Spiritual Health dimension, 25 (50\%) obtained Average scores; 16 (32\%) obtained Good scores and 9 (18\%) obtained very good scores.
With regard to Intellectual Health dimension, 18 (36\%) obtained Good scores; 17 (34\%) obtained Average scores; 10 (20\%) obtained very good scores and 5 (10\%) obtained poor scores.

\section{Conducting intervention programme}

Based on the bench mark issues and preassessment results counseling sessions were organized for a group of 7-10 members. Counselling is often an effective way of dealing with psychosocial and emotional problems of clients facing problems. Anyone (with training) can do it, as long as one has the right attitude and skills. Behaviour is often an open expression of feelings. In order to change problematic behaviour, counselling requires dealing with feelings. Counselling focuses on the client's feelings, thoughts, and ideas that are essential too. Helping clients with problems requires an effective approach.

For the present study, Psycho-Social approach was used while counselling the subjects. 'Psycho' denoting the psychological elements which refers to feelings, thoughts, attitudes, emotions and are normally understood as "internal" and linked to the mind; and 'Social' as the relation between the person and the "external" word, such as the interactions in the family, at work and in general in the sociocultural environment.

The psychosocial approach is an intervention, which looks at the clients' problem in relation to his/her environment. The (Social) environment includes society, family, school, and peers. The Psycho- (logical) part is concerned with mental processes such as feelings, thoughts, behaviour, and motives. The client's problem situation is then analyzed and understood from his/her psychological, social, and cultural perspective. The client's internal capacities and social and cultural resources influence solutions and change. 
Counselling sessions for promoting Psychological wellbeing among Rural Adolescent girls
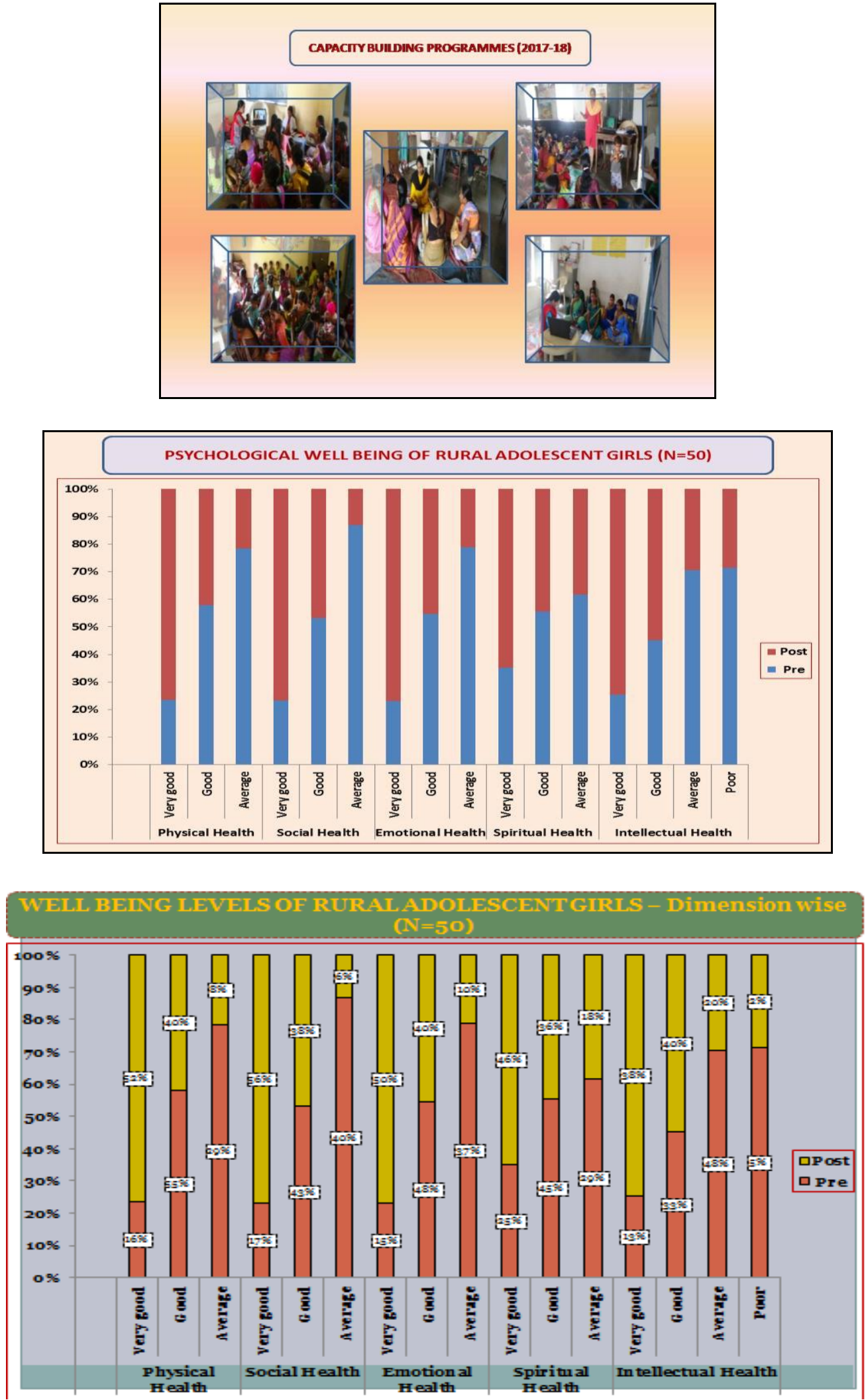
Table.1 Education wise distribution of the selected sample $(\mathrm{N}=50)$

\begin{tabular}{|l|l|l|l|}
\hline Illiterate & Primary school & Secondary school & Inter \\
\hline N \& \% & N \& \% & N \& \% & N \& \% \\
\hline $5(10 \%)$ & $7(14 \%)$ & $22(44 \%)$ & $16(32 \%)$ \\
\hline
\end{tabular}

Table.2 Occupation wise distribution of the selected sample $(\mathrm{N}=50)$

\begin{tabular}{|l|l|l|l|}
$\begin{array}{l}\text { Household work } \\
\text { N \& \% }\end{array}$ & $\begin{array}{l}\text { Fully involved in } \\
\text { agriculture (N \& \%) }\end{array}$ & $\begin{array}{l}\text { Partially involved in } \\
\text { agriculture (N \& \%) }\end{array}$
\end{tabular}

Table. 3 Socio economic status of the sample $(\mathrm{N}=50)$

\begin{tabular}{|l|l|l|}
\hline Socio economic status & Score & Rural adolescent girls (N=50) \\
\hline Upper High & $>76$ & --- \\
\hline High & $61-75$ & --- \\
\hline Upper middle & $46-60$ & $\mathbf{9}(\mathbf{1 8 \%})$ \\
\hline Lower middle & $31-45$ & $\mathbf{3 6}(\mathbf{7 2 \%})$ \\
\hline Poor & $16-30$ & $\mathbf{5}(\mathbf{1 0 \%})$ \\
\hline Very poor & $<15$ & ---- \\
\hline
\end{tabular}

Table.4a Psychological wellbeing among the Rural Adolescent girls ( $N=50)$ Pretest scores Psychological Wellbeing of Rural Adolescent Girls (N=50) -Pretest

\begin{tabular}{|c|c|c|c|}
\hline Dimensions & Category & Score & Adolescent Girls (№ \& \%) \\
\hline \multirow{3}{*}{$\begin{array}{l}\text { Physical } \\
\text { Health }\end{array}$} & Very good & $35-40$ & $10(20 \%)$ \\
\hline & Good & $30-35$ & $28(56 \%)$ \\
\hline & Average & $20-30$ & $12(24 \%)$ \\
\hline \multirow[t]{3}{*}{ Social Health } & Very good & $35-40$ & $13(26 \%)$ \\
\hline & Good & $30-35$ & $28(56 \%)$ \\
\hline & Average & $20-30$ & $9(18 \%)$ \\
\hline \multirow{3}{*}{$\begin{array}{l}\text { Emotional } \\
\text { Health }\end{array}$} & Very good & $35-40$ & $11(22 \%)$ \\
\hline & Good & $30-35$ & $31(62 \%)$ \\
\hline & Average & $20-30$ & $8(16 \%)$ \\
\hline \multirow{3}{*}{$\begin{array}{l}\text { Spiritual } \\
\text { Health }\end{array}$} & Very good & $35-40$ & $9(18 \%)$ \\
\hline & Good & $30-35$ & $16(32 \%)$ \\
\hline & Average & $20-30$ & $25(50 \%)$ \\
\hline \multirow{4}{*}{$\begin{array}{l}\text { Intellectual } \\
\text { Health }\end{array}$} & Very good & $35-40$ & $10(20 \%)$ \\
\hline & Good & $30-35$ & $18(36 \%)$ \\
\hline & Average & $20-30$ & $17(34 \%)$ \\
\hline & Poor & $<20$ & $5(10 \%)$ \\
\hline
\end{tabular}


The following criterion was used to select the sample

\begin{tabular}{|l|l|l|l|l|}
\hline Village & VIII & IX & X & Total \\
\hline Dobbacharla & $\mathbf{1 2}$ & $\mathbf{7}$ & $\mathbf{1 0}$ & $\mathbf{2 9}$ \\
\hline Kollapadkal & $\mathbf{1 2}$ & $\mathbf{8}$ & $\mathbf{8}$ & $\mathbf{2 8}$ \\
\hline Subhanpur & $\mathbf{1 2}$ & $\mathbf{7}$ & $\mathbf{8}$ & $\mathbf{2 7}$ \\
\hline Pendyala & $\mathbf{9}$ & $\mathbf{9}$ & $\mathbf{8}$ & $\mathbf{2 6}$ \\
\hline Total & $\mathbf{4 5}$ & $\mathbf{3 1}$ & $\mathbf{3 4}$ & $\mathbf{1 1 0}$ \\
\hline
\end{tabular}

Impact of Intervention programme: Table.4b Psychological wellbeing of rural adolescent girls $(\mathrm{N}=50)$

\begin{tabular}{ll|l|l|} 
Dimensions & Category & Score & $\begin{array}{l}\text { Post } \\
\text { No \& \% }\end{array}$ \\
\hline Physical Health & Very good & $35-40$ & $26(52 \%)$ \\
& Good & $30-35$ & $20(40 \%)$ \\
\hline \multirow{5}{*}{ Social Health } & Average & $20-30$ & $4(8 \%)$ \\
& Very good & $35-40$ & $28(56 \%)$ \\
& Good & $30-35$ & $19(38 \%)$ \\
\cline { 2 - 3 } Emotional Health & Average & $20-30$ & $3(6 \%)$ \\
& Very good & $35-40$ & $25(50 \%)$ \\
& Good & $30-35$ & $20(40 \%)$ \\
& Average & $20-30$ & $5(10 \%)$ \\
\hline \multirow{5}{*}{ Spiritual Health } & Very good & $35-40$ & $23(46 \%)$ \\
& Good & $30-35$ & $18(36 \%)$ \\
& Average & $20-30$ & $9(18 \%)$ \\
& Very good & $35-40$ & $19(38 \%)$ \\
& Good & $30-35$ & $20(40 \%)$ \\
& Average & $20-30$ & $10(20 \%)$ \\
& Poor & $<20$ & $1(2 \%)$ \\
\hline
\end{tabular}

Table.5 Psychological wellbeing among Rural Adolescent girls (N=50)

\begin{tabular}{|c|c|c|c|c|c|c|c|c|}
\hline \multirow[t]{2}{*}{ Variables } & \multicolumn{2}{|c|}{ Raw scores } & \multicolumn{2}{|l|}{ Mean } & \multicolumn{2}{|l|}{ SD } & \multirow{2}{*}{$\begin{array}{l}\text { Mean } \\
\text { differences } \\
\text { (P1-P) }\end{array}$} & \multirow[t]{2}{*}{ T values } \\
\hline & (P) & (P1) & (P) & (P1) & (P) & (P1) & & \\
\hline PH & 1605 & 1718 & 32.1 & 34.36 & 3.24 & 3.93 & 0.69 & $1.9^{* *}$ \\
\hline SH & 1614 & 1744 & 32.28 & 34.88 & 3.38 & 3.58 & 0.20 & $1.7^{* *}$ \\
\hline EH & 1593 & 1697 & 31.86 & 33.94 & 4.14 & 4.36 & 0.22 & $9.7 * *$ \\
\hline SH & 1511 & 1665 & 30.22 & 33.3 & 4.77 & 4.83 & 0.06 & $1.8^{* *}$ \\
\hline IH & 1479 & 1586 & 29.58 & 31.72 & 5.70 & 5.82 & 0.12 & $3.4^{* *}$ \\
\hline GT & 7802 & 8410 & 156.04 & 168.2 & 19.63 & 20.91 & 1.28 & $1.5^{* *}$ \\
\hline
\end{tabular}


Psychosocial Counselling is a planned intervention between the client and the counsellor to assist the client to alter, improve, or resolve his/her present behaviour, difficulty, or discomforts.

It is a process of helping the client to discover the coping mechanisms that he/she found useful in the past, how they can be used or modified for the present situation, and how to develop new coping mechanisms.

Counselling is about strengthening the ability of the child to solve problems and make decisions and is different from giving advice. Counselling is a process by means of which the helper expresses care and concern towards the person with a problem, and facilitates that person's personal growth and brings about change through self-knowledge.

It is designed to help people to understand and clarify their views, and learn how to reach their self-determined goals through meaningful, well-informed choices, and through the resolution of emotional or interpersonal problems.

The table $4 \mathrm{~b}$ traces the posttest scores of Adolescent girls with regard to Psychological Wellbeing. The scale covers 5 dimensions.

With regard to Physical Health dimension, 26 (52\%) obtained Very good scores; $20(40 \%)$ obtained Good scores; and 4 (8\%) obtained Average scores.

With regard to Social Health dimension, 28 $(56 \%)$ obtained Very good scores; 19 (38\%) obtained Good scores; and $3(6 \%)$ obtained Average scores.

With regard to Emotional Health dimension, 25 (50\%) obtained Very good scores; 20 (40\%) obtained Good scores; and 5 (10\%) obtained Average scores.
With regard to Spiritual Health dimension, 23 $(46 \%)$ obtained Very good scores; $18(36 \%)$ obtained Good scores; and 9 (18\%) obtained Average scores.

With regard to Intellectual Health dimension, 19 (38\%) obtained Very good scores; 20 $(40 \%)$ obtained Good scores; $10 \quad(8 \%)$ obtained Average scores and only one (2\%) obtained.

The table 5 presents the Pre \& Posttest (Raw scores, Means, SD and T values) Scores of Rural Adolescent girls with regard to Subdimensions under Psychological wellbeing. The table shows the progressive increase in the total raw scores across pre-test to posttest, along with the increase in the mean differences, which shows the impact of intervention programme (Couneslling sessions).

$\mathrm{T}$ values between the two means of pre-test and post-test was found to be highly significant, as the calculated values were found to be greater than the tabulated value. The results reflect the effectiveness of Intervention programmes on the Psychological wellbeing of Rural Adolescent girls.

The health of adolescents is integrally shaped by the daily contexts in which they grow and develop. For a large number of adolescents living in poor countries, the primary threats to their health are the devastating daily living conditions brought on by poverty. Consequently, before we delve into the problems of adolescents, it is necessary to understand what is happening to the teen physically, emotionally, cognitively and socially.

The emotional problems are also high in adolescent due to the physical and physiological changes that occur as a part of 
their development. Adolescents need maximum attention and care. Adolescents of today have an intense desire for independence and freedom for self-expression that they deserve. If this need is not satisfied, they will start to deviate from the social norms and social values. Hence counselling units needs to be established in the villages to address the problems of adolescents in time.

\section{References}

Berman SL, Weems CF, Stickle TR (2006). Existential anxiety in adolescents. Prevalence, structure, association with psychological symptoms and identity. $J$ Youth Adol, 35 (3): 303-310

Christopher, J. C. (1999). Situating psychological wellbeing: Exploring the cultural roots of its theory and research. Journal of Counseling and Development, 77, 141-152.
Cripps, K., \& Zyromski, B. (2009). Adolescents' psychological well-being and perceived parental involvement: Implications for parental involvement in middle schools. RMLE Online, 33(4), $1-13$.

Jessica A, Savage. Increasing adolescents' subjective well-being: Effects of a positive psychology in-tervention in comparison to the effects of thera-peutic alliance, youth factors, and expectancy for change [Graduate thesis]. University of South Florida, USA: 2011.

Özen, Ö. (2005). ErgenlerinÖznel I yiOlusDüzeyleri. YüksekLisansTezi, Hacettepe Üniversitesi Sosyal Bilimler Enstitüsü, Ankara.

Ryff, C. D. ve Singer, B. (1998). The contours of positive human health. Psychological Inquiry, 9, 1-28

\section{How to cite this article:}

Nasreen Banu and Yashoda, K. 2018. Impact of Intervention on Psychological Wellbeing of Adolescent Girls from Agrarian Families. Int.J.Curr.Microbiol.App.Sci. 7(11): 2355-2363. doi: https://doi.org/10.20546/ijcmas.2018.711.266 